\title{
Discussion on the Innovation and Breakthrough of TV Advertising Art in the Era of Media Convergence
}

\author{
Zhuo Jin \\ Bozhou University \\ Bozhou, China \\ Marine Convergence Design \\ Pukyong National University \\ Busan, Korea
}

\author{
Chul Soo Kim \\ Dept. of Industrial Design \\ Pukyong National University \\ Busan, Korea
}

\begin{abstract}
With the development of economy, science and technology, the quality and level of fields like industry, agriculture and medical treatment have improved obviously. The scientific and technological progress has promoted the development of TV in our country. The advertising is an indispensable part of $\mathrm{TV}$ and one of the effective ways for enterprises to publicize. After the 21st century, people don't highly praise the traditional advertising art any longer. One of the key topics is how to innovate in the TV advertising art, in order to drive the development of TV industry. This paper researches and analyzes the innovation and breakthrough of TV advertising art in the era of media convergence.
\end{abstract}

Keywords-media convergence; TV advertising art; innovation and breakthrough

\section{INTRODUCTION}

The advertising emerges with the appearance of TV. The development of the current era will inevitably drive the progress of TV industry. In order to conform to the historical trend of the time, the advertising art must have innovation and breakthrough. This paper analyzes and researches the development status of TV advertising art in the era of media convergence and summarizes the valuable information as well as advocates the creative spirit, in order to solve problems in the future.

\section{OVERVIEW ON THE MEDIA CONVERGENCE}

The media convergence refer to a new type media that use media vehicles to integrate different media like broadcast, TV and newspaper with common points in manpower, content and publicity in order to reach the "integration of resources, contents, publicity and profit". With the advanced science and technology especially the internet technology and communication technology, the media convergence present different media forms to the society and then integrate them. The media forms include broadcasting media, TV media, newspaper media, network media and mobile phone media.

As a new type media form, the media convergence organically is to combine the traditional media with the new media and exploit the advantages to the full, playing an important role in the development of modern media. The media convergence transforms the single competition into the competition among multimedia, forming a favorable situation to serve "me".

The media convergence has different reflections at different stages. The definition of media convergence also changes continuously with the era development. The development of media convergence and the actual development situation of the era often go hand in hand. Besides, the media convergence has stable elements, which should be grasped in the analysis of media convergence. According to the media environment with the era development and the modern advanced science and technology, the definition of media convergence consists of the four elements:

- The media convergence integrate different media forms, including the broadcasting media, TV media, newspaper media, network media, mobile phone media and outdoor media.

- The media convergence uses the modern technology platform to realize the integration. The cores of media convergence are the modern internet technology and the communication technology. With the soaring development of science and technology, "the second media age" centering on the internet appears, spreading through the advanced internet technology and communication technology to form the media convergence. The contents covered by the technology platform of media convergence relate to the internet technology and the communication technology, like the internet application technology and the basic network communication technology. The basic network communication technology has abundant contents like the development of Web technology, and the wireless broadband access network. It makes the internet technology get unprecedented development and further drives the formation of the media convergence era. The internet technology and the communication technology under continuous development have become important means of the media convergence. 
- The resources, contents, routes of transmission and sales means are arranged roundly in the era of media convergence. The industry, ways and resources need integration. It is the inevitable trend of era development to integrate the media, including the integration between the contents and technology of information, between the information product and the product offering, as well as between the traditional media and the new media. The integration in the era of media convergence develops through different platforms, transmission modes and development channels. Therefore, all parts in the media convergence are indispensable.

- The media convergence refers to the physical media with media resources, contents, transmission mode and organizational structure. It promotes the transformation and fusion of different media forms according to the characteristics and requirements of the media. The media fusion covers different media forms and elements related to it. It is an obvious characteristic in the era of media convergence to materialize the media convergence. The organization of media convergence is the leaders who present the concrete contents to the public to spread the resource information. The establishment of the media convergence organization contributes to the higher value of media convergence.

The media convergence includes the integration of resources, publicity and profit, showing as follows:

- Resource integration: reasonably integrate the old and new resources (manpower and material resources) and transform the individual service into the common service. The effective integration of information resources promotes the optimization of work in different fields and improves the value and accuracy of information.

- Publicity integration: Establish the new type harmonious complementary media relations and strengthen the communication between media as well as achieve the goal of carrying forward the advantages and eliminating the disadvantages, realizing the invisible association between media and promoting the joint development.

- Profit integration: The active development of media convergence is conducive to the acquisition of benefits, including the economic benefit and the social benefit.

\section{TV MEDIA IN THE ERA OF MEDIA CONVERGENCE}

The TV media convergence refers to a media form that bases on the TV media and realizes the integration of different media through the modern internet technology and communication technology. It combines the traditional TV media with the burgeoning network media and gives full play to the advantages and characteristics of them to realize the maximum benefits.
The TV media convergence appears with the development of the media convergence era. It is the innovative product of the TV media. The characteristics are as follows:

- TV media convergence has massive scale and profound influence. The TV media are popular among the public in today's society. TV enjoys the highest popularizing rate in our country and is still an important channel for people to get information, which is beyond reach of other channels. Therefore, it is promising to combine the media convergence with the TV media.

- TV media convergence is a unidirectional integration based on the TV media. It has the characteristics and contents of TV media. Besides, the media convergence era is unidirectional because of the participation of the radio and TV industry in the decision-making.

- The technology of TV media convergence develops fast. Because of the application of internet technology and communication technology, the TV media convergence has the advanced technology that other media don't have.

- TV media convergence has good development prospects. The TV media convergence have adapted to the era development, changed the traditional TV media and brought great benefits for TV media, which effectively promote the benign development.

In the final analysis, in the traditional media of our country at present, TV media enjoy the leading development. The product scale, technology content and media resource of TV media are the most advanced. It is beyond the reach of other media because of the advantages in long-term production of video contents. TV media have great impact on the public because of the extension to families in the contemporary society. So it has high values to cooperate with the TV media.

The traditional TV media are monopolistic so it has high profits for a long time. However, because of the characteristics of the traditional TV media, we cannot understand the new media correctly. The TV media technology is backward and its true value cannot embody. With the continuous development of new media, in order to meet the demands of the times, the State Administration of Radio, Film, and Television of our country discusses the policies of media convergence, looking forward to the organic combination of the new media and the traditional media, because the TV media industry through the integration of the two in the era of media convergence has brought generous profits for our country. For example, enterprises like China Network Television and South New Media are burgeoning in the era of media convergence. 


\section{INNOVATION AND BREAKTHROUGH OF TV} ADVERTISING ART IN THE ERA OF MEDIA CONVERGENCE

\section{A. TV Advertising Art in the Era of Media Convergence}

The media convergence is not an independent media form but the connection of different media forms to reach the integrated development. Under the effect of media convergence era, the TV advertising art also changes gradually to adapt to the era development.

The TV advertising of our country had a good development prospect in 1980. But with the development of science and technology, the new media appear and it threatens the status of TV. Meanwhile, the TV advertising also faces challenges. The internet media have the advantages that the TV media have and don't have. The internet has integrated in people's life and become an indispensable part of the society. The TV advertising began to flow to the internet media in 2007. Because of lacking the sound material basis, the TV media taking the advertising as the main approach to make profits cannot survive any more. It must reform to strengthen the competitive strength and contend with the internet.

The development of internet mainly depends on the advanced network technology, the dependence on which can develop the TV media similarly. TV media can promote the long-term development of the TV advertising through the effective application of network technology. New media have very important influence on the TV advertising, showing as follow:

- The audiences accept the TV advertising publicity and participate in activities passively, lacking the enthusiasm and interests. Since the appearance of new media, they are freer to accept the advertising information and choose it according to their interests. The new media cater to the public, greatly attacking the traditional publicity forms of TV advertising.

- The new media have diversified channel resources and extensive routes of transmission with valuable practical values. More advertisers prefer the new media. In order to maintain the long-term development, it is necessary to formulate effective and reasonable propagation modes for TV advertising.

- After entering the 21 st century, with the continuous improvement of people's material and culture levels and the progress of science and technology, people have higher requirements. They prefer the new media without advertising to the TV advertising that they need to pay for.

\section{B. The Innovation of TV Advertise Art in the Era of Media Convergence}

In order to exert the function of $\mathrm{TV}$ advertising to compete with network media and gain more benefits, it is necessary to give play to the spirit of innovation and break through the adverse situation.

\section{Innovation of Contents of the TV Advertising Art}

The TV advertising should be novel to attract people's attention. In the production of TV advertising, we should show the overall effect and the connotation to the public and embody the personalized characteristics. People can deeply feel the core contents of TV advertising, which improve the propagation effect of it. Straightaway scenes and propagation methods can be used to strengthen the visual effects of TV advertising. We should express completely, make the contents concise and highlight the key points. In the TV advertising, advertisers pay attention to expressing personal feelings, stimulate people's subconsciousness and use the most sincere emotion to communicate with people to arouse emotional resonance.

The success of TV advertising close relates to people's acceptance of the contents. Innovating the contents of advertising can effective improve people's recognition and attention to the TV advertising. For example, in Guangdong $\mathrm{TV}$, on one hand, let the staff attentively do their own job well; on the other hand, continuously strengthen the training and education for the staff, increase the knowledge reserves of media convergence, change the forms of the traditional TV advertising and innovate in the advertising art based on the traditional TV media. Guangdong TV brings the original works with local culture in the market in the era of media convergence, which has achieved good effects.

\section{Innovation of the Propagation Modes of the TV Advertising Art}

To innovate the propagation modes of the traditional TV advertising. In the era of media convergence, people's attentions are attracted by many things. The product placement can focus people's attention on the advertisement and perfectly show the concrete contents of advertising. It is an important development direction of TV advertising to adapt to the era of media convergence. The product placement means integrating the advertisements in the TV programs, in order to let people accept the advertising and know about the products introduced in it. The product placement eliminates people's tiredness for the traditional forms of TV advertising and further deepens the images of products and the brands in the advertising, getting the effect of killing two birds with one stone. The TV advertising can adopt invisible propagation methods like the product placement to effectively free people from accepting the advertising passively.

Contents popular among people can be used in the TV advertising to attract people's attention. At present, the product placement exists in many films and TV series. For example, the advertising of skin care products in the WETCODE series of the brand DANZ is inserted in the popular film of The Witness. Although people seldom pay attention to the advertising, the advertisement in TV programs will catch the sight of people in a casual way, leaving a good impression of the corporate on people. 


\section{E. Innovation of the Value Assessment of the TV Advertising}

We can calculate all links like the click rate, purchase cost and expectation value of the TV advertising in detail and innovate in the evaluation ways. In the era of media convergence, the advertisement putting and transmission means should be diversified. In order to ensure the advertising investment can gain payback, it is necessary to calculate the contents of the TV advertising accurately. The evaluation patterns of TV advertising are mainly decided by the audience rating of programs and its market shares. With the changes of the time, the value assessment of TV advertising is not confined to the two. More contents have become the key of the value assessment, which provide favorable guarantees for the further development of TV advertising.

\section{F. Innovation of the Marketing Methods of the TV Advertising}

In the era of media convergence, the TV advertising will pay more attention to the brand marketing of TV media, establish the brand image of its own and earn reputation in the society. It should improve continuously, attract the audience through many ways and create the unique brands. Besides, we can make brands for TV advertising and closely link the programs with the advertisements in TV media, so as to publicize the brand and strengthen people's cognition degree and desire to buy products of this brand.

The variety shows of our country in recent years have brought good benefits for many TV stations. For example, the variety shows like Running Man, Go Fighting and Happy Camp have become one of the most popular topics, making many people become famous as well as increasing the advertising revenue. A circulation mode of "the advertising and the programs supplement each other" forms in the TV advertising. It improves the effectiveness and value of the advertisements, getting unexpected effects.

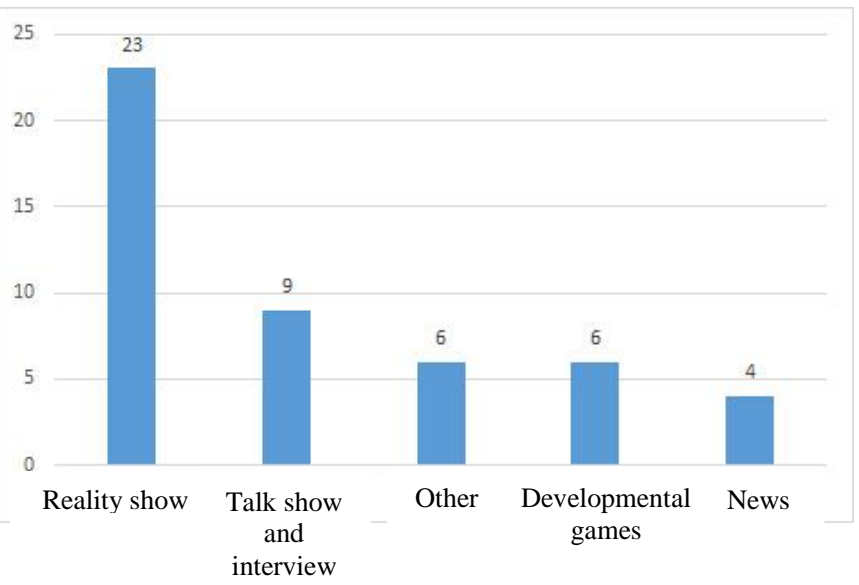

Fig. 1. Analysis graphics for the audience rating of different TV programs.

\section{CONCLUSION}

To sum up, the era of media convergence is the inevitable trend in the development of today's world, having an important significance on the scientific and technological development of our country. The innovation of TV advertising art must be carried out on the basis of the media convergence era, we should grasp the connotation of development and renovate the transmission mode of TV advertising, so as to attract more people to support the development process of TV media.

\section{REFERENCES}

[1] Chen Shaobo. Media Convergence and the Operation and Profit Model under the Perspective of Omnimedia, Journal of Zhejiang University of Media and Communications, the 17th volume, the 5th issue

[2] Shang Yong. Thinking and Exploration on Seeking Life in the "Media convergence", Contemporary TV, the 4th issue in 2009

[3] Zhao Zizhong. Internet TV of New TV Media, Advertising Panorama (comprehensive edition), the 10th issue in 2010

[4] Zhang Baiming. New Interface Form and New Industry Rules, TV Research, the 5th issue in 2011

[5] Song Yi. The Reform of Connotation of TV Media under the Trend of Media Convergence, China Radio and TV Academic Journal, the 11th issue in 2011

[6] Zhang Wei. Economic Analysis on the Media Profit Model, Collection of Papers on Journalism and Communication, the 19th volume

[7] Li Wu. Seven Key Points of the Future Industrial Development for the New Media of Radio and Television, TV Research, the 8th issue in 2011 (261 issues in total). 